\title{
A Review of Ghana's Aquaculture Industry
}

Eric Amenyogbe ${ }^{1,2}$, Gang Chen ${ }^{1,2^{\star}}$, Zhongliang Wang ${ }^{1,2}$, Mingde Lin ${ }^{1,2}$, Xiaoying Lu ${ }^{1,2}$, Denicia Atujona ${ }^{1,3}$ and Emmanuel D Abarike ${ }^{1,3}$

${ }^{1}$ College of Fisheries, Guangdong Ocean University, Zhanjiang, P.R.China

${ }^{2}$ Guangdong Provincial Key Laboratory of Aquaculture in the South China Sea for Aquatic Economic Animals, Zhanjiang, P.R.China

${ }^{3}$ Guangdong Provincial Key Laboratory of Pathogenic Biology and Epidemiology for Aquatic Economic Animals, Zhanjiang, P.R.China

\begin{abstract}
Globally, the aquaculture industry has seen significant development through increased fish production, as a result of increased demand for fish and fish products. Ghana's aquaculture sector has seen significant growth in recent years, due to the government/World Bank-funded fisheries program through Ministry of Fisheries and Aquaculture Development (MOFAD). The national aquaculture production grew from over 32,512 MT/y in 2013 to $52,470.49 \mathrm{MT} / \mathrm{y}$, representing $11.3 \%$ of the national harvest, in 2016 . Aquaculture production is projected to hit 72,000 Tons, representing $15 \%$ of national fish production, in the next 3-5 years. Despite the significant growth, the sector is faced with several challenges related to management and production problems. For instance, limited knowledge of modern aquaculture techniques, inadequate supplies of improved seed, lack of continuing aquaculture policy direction, and inadequate funding for research. Despite the challenges, there are some fantastic opportunities in Ghana's aquaculture industry such as the production of live fish food, marine fish and shellfish culture, integrated fish farming, the culture of indigenous fish species, and investment in the fish feed industry. In this review, we explore the current state, obstacles, potentials, and future opportunities for Ghana's aquaculture sector. We propose measures that should be looked at to overcome the challenges as well as improve production in the sector.
\end{abstract}

Keywords: Aquaculture; Ghana; Obstacles; Potentials

\section{Introduction}

The growth of the global aquaculture industry has been sporadic over the last 50 years, and the global production capabilities of culture and capture fisheries are almost comparable [1]. In Africa, fish culture has grown tremendously due to advances in feed formulation, and the use of better culture facilities such as cages [2]. Even as Asia has become elephantine in aquaculture, Africa as a continent is yet to report any important additions of aquaculture on the world ordered series even though there are many available natural resources in many regions of the continent [3]. Aquaculture continues to grow more rapidly than all other animal producing sectors. According to FAO [4], developing countries" contribution by weight increased from $73 \%$ in 1979 to $90 \%$ in 1998. However, this dramatic increase in production is skewed on a regional basis in favour of Asia. For example, in 1998, aquaculture productions by weight according to the region were as follows: Europe, about 5\%; South America, less than 2\%; Africa and Oceania, about $0.5 \%$ each [5,6]. Moreover, according to FAO (2000), the numbers of fish farmers in the world increased from 7.07 million in 1998 to 7.47 million in 2000. The corresponding numbers for 1998 (2000) by region were: Asia, 6.67 (7.13) million; North and Central America, 191,000 (190,000); Africa 56,000 (75,000); South America, 41,000 (41,000) and Oceania $5,000(5,000)$. Taken the above into consideration, Africa continues to be a minor player in the global aquaculture industry even though the continent has a natural potential for aquaculture production. Tilapia production which is aboriginal to the African continent has not seen any important growth or development. Nevertheless, according to FAO Africa still has a great potential. For instance, the black tiger shrimp (Penaeus mondon) which is cultured in Madagascar, Eucheuma seaweed in Tanzania and as well as abalone (Haliotis spp) in South Africa [7].

The most prevalent cultured fish species in Ghana presently are Nile tilapia (Oreochromis niloticus), African catfish, (Clarias gariepinus), and African arowana (Heterotis niloticus) [8,9]. Currently, there is no major Marine culture in Ghana This is because of lack of technology, expertise and cultural problems such as misunderstanding over ownership of land, and none existent of proper policies among others (Mr. Coffie
Oye, personal communication, November 20, 2014). With population growth escalating to unsustainable levels and increasing food insecurity, Ghana's dwindling fish supply from capture fisheries are inadequate to provide cheap protein for the growing population [9]. Natural water bodies such as Lake Volta, River Bosomtwi and River Pra which have also been instrumental in fish production are facing their share of challenges, ranging from pollution due to mining to the reduction of water levels that compromise fisheries [9]. In the face of these problems, aquaculture is the best opportunity to bridge the escalating gap between supply and demand for fish. For aquaculture to register substantial growth and meet its potential, development of Ghana's aquaculture must be relooked. This paper explores the current state, obstacles, potentials, and future opportunities for Ghana's aquaculture sector. The review focuses on the potential of current aquaculture production systems and opportunities for improvement. The current aquaculture species and inputs in Ghana's aquaculture sector are also discussed.

\section{Overview of Ghana's' aquaculture}

Ghana is full of rivers, seas, dams, and dugouts, all of which make aquaculture practicable countrywide [8]. With prosperous environmental and institutional conditions of suited topography and climate and authority support, copiousness of resourceful human resources, an abundance of natural water bodies and high demand for fish. Ghana is making quick, great pace in aquaculture development [9].

*Corresponding author: Gang Chen, College of Fisheries, Guangdong Ocean University, Zhanjiang 524025, China, Tel: +8613702720713; E-mail: gdoucg@126.com

Received July 19, 2018; Accepted August 13, 2018; Published August 17, 2018

Citation: Amenyogbe E, Chen G, Wang Z, Lin M, Lu X, et al. (2018) A Review of Ghana's Aquaculture Industry. J Aquac Res Development 9: 545. doi: 10.4172/21559546.1000545

Copyright: @ 2018 Amenyogbe E, et al. This is an open-access article distributed under the terms of the Creative Commons Attribution License, which permits unrestricted use, distribution, and reproduction in any medium, provided the original author and source are credited. 
Ghana's maraud into aquaculture started with the initiatory of the colonial administration led by British in 1953 when the first ponds were built as hatcheries to help the culture-based fishery development programme and as a way of appurtenance the national taste for fish and increasing livelihood chances [4,10]. After-independence in 1957, the government espouse a policy to constructs fishponds within all irrigation system in the country most especially in the northern part of the country [11]. The government-built irrigation dams under a policy of converting 5 percent of the facilities into fish farms, where possible. In recent times, nevertheless, a rapid gain in production has led to the launching of numerous cages in Volta Lake. The participation of commercial investors in the aquaculture sector had automatically and neutered the face of aquaculture in Ghana [11]. Undoubtedly, aquaculture is a moderately new business in Ghana; its pattern is becoming countrywide, particularly in the Ashanti, Central, Eastern, Volta and Western regions of Ghana. The aquaculture subsector consists of many operators who pattern on a subsistence level which use the semi-intensive system to culture fish in earthen ponds. Majority of farmers also employed the extensive culture system by the used of dams, dugout, ponds, and reservoirs for fish culture [12]. Commercial fish farmers who use intensive culture systems though in the minority produce about 75 percent of Ghana's total aquaculture production [13]. Pond culture system is the prevailing production system in the southern and central part of the country, which covers about 98 percent of farms, which is also primarily small scale and semi-intensive in status [14]. In a couple of years past, nevertheless, the prevailing culture system for tilapia production has changed, and the immense bulk of cultured tilapia is now cultured intensively in cages, especially in Lake Volta [11].

Holding systems used in Ghana are floating cages, earthen ponds, and concrete tanks. Majority of farmed fish in Ghana, about 90 percent are from cage culture system with the remaining percentage from ponds [13]. Cage farming system is predominantly on Lake Volta and has become the fastest business activities at about an annual growth rate of 73 percent between 2010 and 2016. The records show that the first cage fish farm in Ghana was established in 2001 [14]. Most of the farms do not have hatcheries but buy fingerlings from other hatcheries for their production. Ordinarily, medium scale farmers buy fingerlings from large-scale farmers and other sources such as Water Research Institute, Aquaculture Research, and Development Centre at Akosombo (WRIARDEC). Usually, they depend on WRI-ARDEC at Akosombo for technical advice [15].

Cage system of farming presently accounts for about 2 percent of farms by number but much greater bycatch output [13]. The considerable bulk of cage farms are situated in the Eastern Region particular Asuogyaman District, with a majority of small-scale cage farms situated between Akosombo Dam and Kpong Dam. Several small to medium-sized cage farms can also be found in areas such as Kpeve in South Dayi District of Volta Region, Akuse in Lower Manya Krobo District and Akrusu in Upper Manya Krobo District of Eastern Region [11]. Aquaculture in the Northern, Upper East, and Upper West regions in the north of Ghana are mostly carried out in extensive or culture-based fisheries at irrigation sites, reservoirs and dams. A majority of large-scale commercial farmers runs Cage culture system in Ghana on Lake Volta while a minority or few run earthen ponds and cage systems [9]. Tilapia (Oreochromis niloticus) is the dominant and preferable fish species for farming and consumers in Ghana. Tilapia species account for over 80 percent of the farmed fish harvest, with a present production of little over 52,000 tonnes per year [16]. Catfish Clarias gariepinus and Heterobranchus species constitute the remaining 20 percent of farmed species. There have been cultivations of Heterotis niloticus, silver carp and tiger prawn (Penaeus monodom) mostly for experimental intent. Shellfish farming is non-existence in Ghana. Nevertheless, Government recently announced plans to improve shrimp production with intentions of supplying shrimp larvae to farmers which remain a dream though [17]. The most plebeian auxiliary feeds used by fish farmers in Ghana, especially many smallscale farmers, includes wheat bran, maize bran, rice bran and brans of other cereals, of which are readily accessible on the local market [18]. Commercial floating feed, which is comparatively expensive, is used by only a few farmers. Famers still import Commercial feeds to Ghana even though in 2011, a feed mill was established in Ghana because the mill is not able to meet the demand of farmers. The high cost of fish feed in Ghana is mostly responsible for the high costs of aquaculture production. Feed cost is $70 \%$ of the total production costs, and the imported feeds are mostly about 30 percent costlier than the locally-manufactured feeds [9]. Ghana presently has about 5,000 fish farmers operating approximately 19,000 fish ponds and cages [19]. The aquaculture end product for 2013 was a little over 30,000 metric tonnes of fish, out of which nearly 88 percent came from cages [13]. To induce aquaculture growth, the Ministry of Fisheries and Aquaculture Development has forbidden the imports of farmed fish, in particular, flash-frozen tilapia. The ministry also set up the Ghana National Aquaculture Development Plan (GNADP) with challenging production target of 100000 metric tonnes of fish at the end of 2016, which is the increments from the 2010 production volume of 10200 tonnes and the 27000 tonne production in 2012 respectively [19]. The program aims to ameliorate the practice, direction, and evolution of aquaculture as a possible business activity and its execution is expected to cost 85 million United State dollars. It was developed in quislingism with the Food and Agriculture Organization (FAO), The National Aquaculture Strategic Framework (2006) and the Ghana National Aquaculture Development Plan (GNADP) (2013) aimed at the development and management and improvement of Ghana's aquaculture [16].

\section{Size and importance of the aquaculture sector}

The aquaculture sector in Ghana plays a significant role in the national economy. It contributes about $3 \%$ to $5 \%$ to the Gross Domestic Product (GDP) and provides employment opportunities to the populace [20]. Ghana's current fish production from aquaculture is 52,470.49 metric tonnes a year [16]. The most important source of animal protein in every part of the country, poor or rich, village or cities comes from fish in Ghana [21]. About 10 percent of Ghana population is dependent on the aquaculture sector for their livelihoods [22]. According to Ref [18], fish is the only source of the protein whose shelf life can be readily improved through low-cost engineering such as smoking, salting, drying, and readily accessible in remote markets. About 140 fish species are found in Lake Volta and the livelihood of approximately 300000 Ghanaians who live around the lake [8]. It is also estimated that 1.5-2 million people directly or indirectly rely on or support these fishers include their wives, children, close relatives, canoe carvers, input suppliers, and office workers for industrial fleet Ibid $[22,23]$. The aquaculture sector provides employment, livelihood support, poverty reduction, food security, and foreign exchange. From perspectives of gender, the Aquaculture sector is very vital, while the men are engaged in the main culture activities, the women are involved with the post-harvest activities such as processing and trading [4]. The demand for fish and fish product has been growing due to population increase. Furthermore, due to the ever-growing population capture fisheries is not enough to meet the demands of the people for fish [18]. Due to this, the development of aquaculture is critical and nonnegotiable to the Ghanaian government to serve as one of the strategies 
to bridge the gap between demand and supply of fish and to produce in excess for exports. Shown in Figure 1 is some statistics of the fish production and contribution by the sector.

\section{Forms of aquaculture in Ghana}

History has it that, three forms of aquaculture traditionally exist in Ghana. These are acadjas or brush-parks in lagoons and reservoirs; hatsis (fish holes) and whedos (mini-dams) in coastal lagoons; and afani or freshwater clams (Egeria radiata) in the lower Volta, where young clams are gathered and "planted" in "owned" areas of the river [24]. Present forms of aquaculture are said to be introduced some 60 years ago. The modern form of aquaculture was started with ponds culture, and this type of aquaculture is still prevalent in Ghana presently [25]. The bottom and sides of the ponds are built with concrete. Aquaculture in Ghana mainly consists of three species namely; tilapia, catfish, and Heterotis. There were some attempts of introductions regarding some other species. These include Oreochromis macrochir, common and silver carp, and the tiger prawn (Penaues monodon) [22]. Advancement efforts are chiefly focused on freshwater as the Intermediate of culture. Some attempts have been made in brackish water on Penaues monodon [22]. Nevertheless, no efforts have been executed directly on marine environments. Regarding culture, ponds, pens, cages or raceways systems are used in Ghana. It is costly to operate Cages and raceways regarding structure and costs of feeding as compared to pens; the cost of feeding is not the much expensive example for a plankton feeder like O. niloticus. One primary concern about the pens is that it has not got a suitable environment for its establishments due to the following reasons, the water levels, example reservoirs, and the Volta Lake varies over the year. In situations like that, the level of pens has to be high that even if the water level rises, the inducement to remove the pens may not arouse [11]. Again, when fishers are also fishing close pens sites or close to the place, the issues of theft are a major concern and the fishermen. Besides, they sell their captured fishes at lower prices which the fish farmers cannot compete. This gives room for pond aquaculture to be the basis of fish culture in Ghana for many decades to come most especially when freshwater quality is becoming too much of a concern [11]. Notwithstanding, one vintage of cages and pens is that it allows the use of water by other users because of the high opportunity cost of water. The only obstacle now is to find a solution to the problem of varying water levels [11]. Currently the majority of large-scale commercial farmers runs Cage culture system in Ghana on Lake Volta while a minority or few run earthen ponds and cage systems [9].

\section{Research, establishments and government support}

The government of Ghana aims to boost aquaculture production to a minimum of five-year possible time, but this has not been achieved. Nevertheless, there varies opinion as to whether shrimp can be cultured [11]. Though some efforts have been made to boost shrimp farming in West Africa, there is nothing to show regarding success [22]. The case of the lagoons of La Côte d" Ivoire is an example. More so, the market for shrimp in West Africa has been inundated due to importations of shrimps mostly from Asia and other parts of the world [2]. Freshwater culture has the possibilities for fin-fish and crustaceans, yet only finfish culture is being cultured presently. Freshwater prawns have been considered as species of culture for long until now no fresh water crustacean has been cultured commercially [11]. There was an endeavor to culture $M$. rosenbergi and $M$. vollenhoveni but without any sustained commercial aquaculture emerging [26]. The country wanted to culture $M$. rosenbergi because the vantage was that there is already applied science that can be used [22]. The challenge is that the market is precariousness both worldwide. However, there is assurance when it comes to market in the case of $M$. vollenhoveni, in West Africa but applied science is not until now evolved. In this situation, the second scheme would be to evolve a culture of applied science for M. vollenhoveni [2]. There are many establishments which are involved in aquaculture development in Ghana. The following are the major and most important institutions that are involved Ministry of Fisheries and Aquaculture Development, Fisheries Commission, Water Research Institute (WRI), Environmental Protection Agency (EPA), Universities and Water Research Council (WRC). There are no private research institutions involved in aquaculture in the country [9]. Notwithstanding, the Water Research Council is the only aquaculture research institution in the country even though tertiary institutions especially the universities also are researching aquaculture. Water Research Institute operates the Aquaculture Research and Development Centre explicitly in Akosombo on Lake Volta, from where they do research and development activities related to aquaculture production systems and provide a range of technical support to the aquaculture sector, including the sale of fish seed to farmers [11]. There are many researchers ongoing. These involve feed trials, the Genetic make-up of the Volta Oreochromis niloticus [26], the composition of the agricultural spin-off to assist in feed formulation, IAA trials in the Akwapim Valley and manual sexing of Tilapia fingerling. Regarding fish health, the farmers are being educated on many fish health issues. There are also many fish disease survey ongoing. To improve the aquaculture sector with human resources, the public Universities in Ghana namely: the University of Ghana, University of Cape Coast. Also, the University of Natural Resource and Energy, Kwame Nkrumah University of Science and Technology, and University of Development Studies conduct
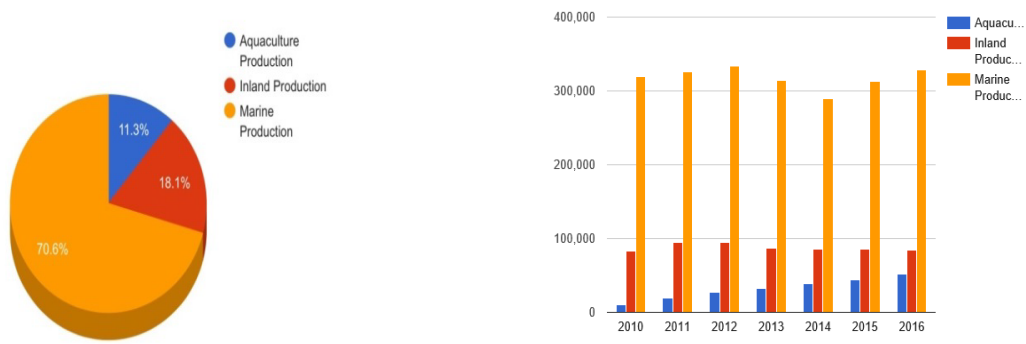

Figure 1: Fish production sector contribution (A) and fish production (B) Source: Ministry of Fisheries and Aquaculture Development. 
research and are directly involved in the training of personnel in aquaculture and related subjects at the levels of BSc, MPhil/MSc and Ph.D [9]. Also, Agriculture Colleges provides Technical knowledge in aquaculture to potential Technical and Extension Officers, who usually work as field assistants at MOFAD, Research Institutions and Fish Farms [27]. The CSIR - Water Research Institute (WRI) is the only public research institution with a mandate to conduct research and development in and Aquaculture [27]. WRI is actively involved in building capacities, both locally and within the West African region, of farmers, MOFAD fisheries officers, university students through parttime tuition and National Service Personnel attached to the Institute. Successful National Service persons from WRI usually get engaged to assist in the technical management of most farms including large commercial farms. Knowledge in aquaculture is also developed through regular industrial attachments of interested persons to WRI or some working commercial farms [15].

\section{Ghana's fish feed industry}

According to Craig and his colleagues [28], the fish feed is a key component in any fish-farming business because fish nutrition accounts for $40 \%$ to $50 \%$ of the total variable production costs on the fish farm [29]. One of the major challenges in Ghana's aquaculture is the lack of efficient and inexpensive farm-made feeds for all stages of fish growth. As a result of the increasing demand for fish feed, most feed sold by vendors are below standard [14]. Commercial fish feeds for tilapia usually contain $24 \%$ to $28 \%$ crude protein, but due to the expensive nature of the fish meal, peasant farmers use feeds with lower protein levels such as rice bran, brewers waste, groundout brand, or maize bran Anchovy popularly among others [11]. The formulation of farm-made feeds mainly depends on the costs of ingredients rather than the nutritional requirement of the fish [30]. Based on studies by Liti et al. [31], fish fed maize or wheat bran grew significantly faster than those fed rice bran. Maize bran is better than wheat bran because of lower levels of fibre.

\section{Ghana's seed fish sector}

According to Ministry of Fisheries and Aquaculture Development, Inadequate or insufficient availability and quality of fingerlings for stocking are keys encumber for the development of Ghana's aquaculture. Also, the demand for African catfish C. gariepinus fingerlings for stocking fish ponds has increased and made room for farmers or researchers to look at, this species has also been reported to be used as bait fish in capture fisheries, leading to increased demand over the years (Ministry of Fisheries and Aquaculture Development,). Today, the total demand for both catfish and tilapia fingerling is estimated at a very high demand. Even though the government has been making lots of efforts to improve existing fish breeding centers such as WRI-ARDEC and Pilot Aquaculture Development Center (PAC), this massive annual demand for fingerlings cannot be attained unless private sector supports (Ministry of Fisheries and Aquaculture Development). Also, the quality of the fingerling supplied needs to be ensured. Concerning Food and Agriculture Organization (FAO), to achieve good quality seed fish, aquaculture experts have encouraged measures to obtain same-sex fingerlings using sex reversal and hybridization techniques. The initiatives which are used by the research centers but are unpopular among fish farmers due to the lack of technical knowledge and facilities required. These are some areas that private investors could look at regarding investment in fish farming in Ghana. Ghana's government through the Ministry of Fisheries and Aquaculture Development [32] brings together researchers, fisheries officers, fish farmers has authenticated fish hatcheries nationwide and put together seed fish quality standards, which has in a way solved problems of substandard seed fish in the aquaculture market.

\section{Obstacles in Ghana's aquaculture sector}

As in many African countries, after many years of fish farming in Ghana, the country is still suffering from basic challenges. Ghana's aquaculture industry suffers from limited knowledge of aquaculture investment and lack of information on the economic performance of various fish farming systems. More importantly, the inadequate supply of quality feed and seed fish has been a longstanding hindrance to the growth of aquaculture. Farmers have failed in fish farming because they incur huge losses due to the use of low-quality seed and feed [11]. Other problems affecting the growth of aquaculture include lack of a comprehensive policy, poor extension services, lack of robust needbased research coupled with low funding, lack of investment by the private sector, and unfocused promotion of aquaculture through many institutions $[2,33]$. Indeed, improvements in fish culture systems, such as increasing cage and pond productivity, introducing other efficient systems, and developing a sustainable mechanism for production and distribution of pond inputs, are challenges that still need to be addressed. With the explosive interest in fish farming stimulated by the Ministry of Fisheries and Aquaculture Development, new challenges from environmental pollution, biosecurity, and the spread of diseases has also emerged and must be addressed. Maintenance of water quality is one major challenge faced by fish farmers. Very often dissolved oxygen can quickly be altered by decomposition of fecal waste harming their delicate gills and lead to other problems. Sadly, many farmers lack the skills to handle such problems [34].

\section{Diseases}

Outbreaks of fish diseases adversely affect the production of aquaculture $[35,36]$. Disease outbreaks in fish culture are more rampant in the tropics because of adverse weather condition and the limited measures available to remedy the situation, and as a result, many losses have occurred in the fish farming industry due to diseases outbreaks [37,38]. In Africa, diseases are a major problem in large aquaculture production countries such as Egypt [39] and South Africa [40]. Therefore, large data sets on the diseases that hamper the aquaculture industry exist. Although in Ghana, diseases causing organisms such as parasites, fungi, bacterial and viral pathogens exist in many water bodies, no report was found on their effects on the aquaculture industry Fish production has many prospects in Ghana, due to the availability of a suitable environment; however, there may be the need to take measures to prevent the occurrence of diseases which often is associated with increased production through wide adaptation of intensive farming practices [41].

\section{Processing and marketing of aquaculture products in Ghana}

In Ghana, fish are preserved by smoking, salting, frying, and recently cold storage. Tilapia, which is the commonly farmed fish, is mostly sold fresh at the farm or stored in cold stores and sold [42]. Catfish, on the other hand, are commonly smoked dried before sale [43]. The absence of cold storage facilities in the aquaculture industry in Ghana makes the distribution and marketing of fresh fish limited [15]. The market system of aquaculture in Ghana lacks competitiveness, and no largescale global markets exist for the fish farmed. Besides, the Ghanaian aquaculture produces high-cost fish, which are none competitive with low-cost farmed tilapia from other countries including China. Ghanaians generally prefer fresh tilapia to frozen ones [11]; however, 
Citation: Amenyogbe E, Chen G, Wang Z, Lin M, Lu X, et al. (2018) A Review of Ghana's Aquaculture Industry. J Aquac Res Development 9: 545. doi: 10.4172/21559546.1000545

Page 5 of 6

there is high propensity to patronize cheaper frozen fish when available [44].

\section{Potentials for present and future aquaculture development in Ghana}

The water bodies in Ghana abounds with many culturable fish species, including mullet, milkfish, prawns, mussels, oysters, and abalone. These fishes seem to perform better in cultivable conditions than in natural waters which will also help increase food availability [2]. Although these fishes are highly cherished and consumed by many locals, currently their culture is non-existent. The presence of these fish in Ghanaian water bodies is a good indication of potential culture and could be tapped to create employment. Ghana can emulate the success of Vietnam, which has become one of the leading traders in Artemia cysts in the world market and also can exploit other marine fish species such as groupers which are essential culture species in Asia. Cage aquaculture shows a more sustained growth than pond aquaculture. Vertical integration of input supply, local aqua feed production, production of quality fingerlings in controlled conditions for safety and whole year-round intensive production of fingerlings constitute the basis of a substantial cage farming industry [9]. Ghana has the opportunity to exploit this opportunity and join other world leaders in the Artemia cyst trade. The much reported overexploited of capture fisheries in Ghana's natural waters are clear. Aquaculture is the bacon of hope to alleviate the burden of fish shortages. The enormous potential of Ghana's aquaculture cannot be overemphasized enough [45]. There is increased interest in aquaculture most especially by the youth. The successful evolution of sustainable fish farming lies in the packaging of aquaculture as a possible investment chance whereby potential investors identify opportunities to be financially rewarding in a "winwin" fashion [46]. As noted here, the marine sector harbours the most lucrative opportunities and should be given particular focus. Other farming systems such as integrated fish farming can also be exploited.

There is the need for the industry players for instance farmers and the government to collaborate as well as create linkages that can serve as a means for the exchange of information and ideas. Mechanisms must also be developed to link small farmers to local, urban, regional, and global markets. Rural extension programs are needed to educate farmers and enhance their capacities to adopt new aquaculture technologies. Governments must continue to put more effort into creating an environment which will enable the private sector to invest in strategic areas such as feed and financial sectors. Specific and practical policies should be tailored to adequately respond to local aquaculture conditions instead of impractical highly intensive aquaculture systems. The Cooperative Extension Service must be provided to farmers on water quality in workshops for fish farmers. These workshops should provide hands-on experience for instance how to test and interpret water quality as well the measures to take to maintain good water environment for fish growth. In the area of fish feed, it is a vital area of interest where private businesses can invest because until now Ghana has only one recognized fish feed company which produces below the needed quantity, about $80-90 \%$ of fish feeds are imported annually. There is a need to implement the promotion of value addition in the fisheries and aquaculture sector and the improvement of livelihoods in the fisheries communities. Also, value addition in the production chain of aquaculture products is necessary to reduced post-harvest losses, reducing handling costs and producing higher value products as stipulated in Fisheries and Aquaculture Sector Development Plan of Ghana. Fish diseases constitute a significant threat to the survivor of the aquaculture industry in Ghana; there must be a drastic effort by the government and all stakeholders to research and educate farmers on the control and preventive measures. There is the need for research into the potential of other culturable niloticus species especially marine species.

\section{Funding}

This work was supported by China Agriculture research system (CARS-47).

\section{Submission Declaration and Verification}

This article to be considered for publication has not been published previously and is not under consideration for publication elsewhere.

\section{Authors' Contributions}

Gang Chen and Zhongliang conceived the idea. Denicia Atujona, Mingde Lin, and Xiaoying Lu gathered literature. Eric Amenyogbe and Emmanuel Delwin Abarike drafted and proofread the manuscript.

\section{Conflict of Interest}

The authors declare that there are no conflicts of interest.

\section{References}

1. Food and Agriculture Organization of the United Nations (2012) The State of World Fisheries and Aquaculture. FAO, Rome, IT.

2. Munguti JM, Kim J, Ogello EO (2014)An overview of KenyanAquaculture: Current status, challenges, and opportunities for future development. Fish Aquat Sci 17 1-11.

3. Food and Agriculture Organization of the United Nations (2010) Securing sustainable small-scale fisheries: Bringing together responsible fisheries and social development. RAP Publication. In: APFIC/FAO Regional Consultative Workshop. Food and Agriculture Organization of the United Nations, Bangkok, TH, pp: 1-56.

4. FAO (2000) National aquaculture sector overview in Ghana: Fisheries and aquaculture 2: 1 .

5. FAO (2006) Publications related to aquaculture for Ghana.

6. Kooiman J, Bavinck M, Jentoft S, Pullin R (2005) Fish for Life: Interactive governance for fisheries.

7. FAO (2007) Paying farmers for environmental services.

8. Béné C (2007) Diagnostic study of the Volta Basin fisheries. Part 1: Overview of the Volta Basin fisheries resources. WorldFish p: 31

9. Rurangwa E, Agyakwah SK, Boon H, Bolman BC (2015) Development of aquaculture in Ghana, analysis of the fish value chain and potential business cases. IMARES report C021/15.

10. FAO (2005) Results of the 2004 baseline survey of Ghanaian fish farmers. FAO Regional office for Africa. Accra p: 77.

11. Kassam L (2014) Aquaculture, and food security, poverty alleviation and nutrition in Ghana: Case study prepared for the aquaculture for food security poverty alleviation, and nutrition project. World Fish, Penang, Malaysia. Project Report J 2: 1.

12. Koranteng KA, Bortey A, Yeboah DA (2006) The state of the world fisheries from a fish-worker perspective: The Ghanaian situation p: 88

13. MOFAD (2016) Annualreport-2017, Ministry of Fisheries and Aquaculture Development.

14. Kaunda KW, Abban EK, Peacock N (2010) Aquaculture in Ghana: Its potential to be a significant contributor to national fish supplies. Unpublished manuscript.

15. Antwi-Asare TO, Abbey EN (2011) Fishery value chain analysis Ghana.

16. The Republic of Ghana (2016) Ministry of Fisheries and Aquaculture Development. Fisheries Commission, Ghana.

17. The Fish Site (2015) Ghana aquaculture production grows 20\% in 2015 2: 1

18. Aggrey-Fynn E (2001) The contribution of the fisheries sector to Ghana's economy. A paper prepared on behalf of the $\mathrm{FAO}$ as an input into the sustainable fisheries livelihoods study.

19. MOFA (2012) Ghana National Aquaculture Development Plan (GNADP) Fisheries Commission, Ministry of Food and Agriculture p: 78 
Citation: Amenyogbe E, Chen G, Wang Z, Lin M, Lu X, et al. (2018) A Review of Ghana's Aquaculture Industry. J Aquac Res Development 9: 545. doi: 10.4172/21559546.1000545

20. Bank of Ghana (2008) The fishing subsector and Ghana's economy.

21. Anon (2003) Disposal and re-utilization of fish and processing waste (including aquaculture wastes). Nautilus Consultants (Ireland) Ltd DK/01/03.

22. Hiheglo PK (2008) Aquaculture in Ghana: Prospects, challenges, antidotes and feature perspectives. Publisher University of Tromso.

23. FAO Aquaculture Production 2004 (2005) Yearbook of Fishery StatisticsVol.96/2. Food and Agriculture Organization of the United Nations, Rome, Italy.

24. FAO (2008) BIOFUELS: Prospects, Risks and Opportunities.

25. Prein M, Ofori JK (1996) Research for the future development of aquaculture in Ghana. International631, 0718 Makati City, Metro Manila, Philippines.

26. https://www.csir.org.gh/images/CSIR-WRI_Reports/Annual_Report_2011.pdf.

27. Asmah $R$ (2008) Development potential and financial viability of fish farming in Ghana.

28. Craig S, Helfrich LA (2002) Understanding fish nutrition, Feeds and Feeding J. Virginia creative extension, Petersburg, VA, US pp: 26-27.

29. Munguti JM, Charo-Karisa H (2011) Fish Feeds and aquaculture development in Kenya. In: Samaki news: Aquaculture development in Kenya towards food security, poverty alleviation and wealth creation [J] 7: 27-29.

30. Cobbina R (2010) Aquaculture in Ghana: Economic perspectives of Ghanaian aquaculture for policy development.

31. Liti DM, Mugo RM, Munguti JM, Waidbacher H (2006) Growth and economic performance of Nile tilapia (Oreochromis niloticus $L$.) fed on three brans (maize, wheat, and rice) in fertilized ponds [J]. Aquac Nutr 12: 239-245.

32. Modern Ghana (2013) Ghana launches $\$ 85$ million aquaculture development plan.

33. Gitonga NK, Mbugua H, Nyandati B (2004) Samaki news: A magazine of the Department of Fisheries of Kenya Motif Creative Arts Ltd. Nairobi, KE New approach to fish farming extension in Kenya pp: 8-12.

34. Hijran YY, Lidia R, Juhani P, Elena M, David D, et al. (2017) Fish welfare in aquaponic systems: Its relation to water quality with an emphasis on feed and faeces: A review. Water 9: 13

35. Subasinghe RP, Phillips MJ (2002) Aquatic animal health management Opportunities and challenges for rural, small-scale aquaculture and enhanced fisheries development: Workshop introductory remarks. FAO fisheries technical paper pp: $1-5$

36. The Republic of Ghana (2015) Ministry of fisheries and aquaculture development. Fisheries Commission, Ghana.

37. Akoll P, Mwanja WW (2012) Fish health status, research, and management in East Africa: Past and present. Afr J Aquat Sci 37: 117-129.

38. Leung TLF, Bates AE (2013) More rapid and severe disease outbreaks for aquaculture at the tropics: Implications for food security. J Appl Ecol 50: 215-222.

39. Aly SM (2013) A review of fish diseases in the Egyptian aquaculture sector 2: 1.

40. Brückner GK (1996) Review of disease control in aquaculture in the Republic of South Africa. Rev Sci Tech. 15: 703-710.

41. Essuman KF (1992) A study on processing, marketing and consumption of cured fish in West Africa: Fermented Fish in Africa. FAO Fisheries Technical Report. No: 329.

42. Sefa-Dedeh S (1995) Traditional fish processes: Technology, quality \& evaluation. Workshop on Seeking Improvement in Fish Technology in West Africa. IDAF Technical Report. No: 66

43. Ward A (2003) A study of the trade in smoked dried fish from West Africa to the United Kingdom. FAO Fisheries Circular No. 981. FAO, Rome.

44. Ann G, Alan P, Ellen Owusu-Adjei (2011) Smoked marine fish from western region, Ghana: Value chain assessment. The World Fish Center p: 41.

45. The Republic of Ghana (2014) Ministry of Fisheries and Aquaculture Development.

46. Mofa (2011) Republic of Ghana Fisheries and Aquaculture Sector Development Plan 2011-2016. 